\title{
Aplicação do método do potencial espontâneo na investigação do fluxo subterrâneo na área do lixão de Cidade Nova, em Natal/RN.
}

\author{
Bruno Raphael Morais de Vasconcelos (DGEF/UFRN), Josibel Gomes de Oliveira Júnior (DGEF/UFRN).
}

Copyright 2014, SBGf - Sociedade Brasileira de Geofísica

Este texto foi preparado para a apresentação no VI Simpósio Brasileiro de Geofísica, Porto Alegre, 14 a 16 de outubro de 2014. Seu conteúdo foi revisado pelo Comitê Técnico do VI SimBGf, mas não necessariamente representa a opinião da SBGf ou de seus associados. E proibida a reprodução total ou parcial deste material para propósitos comerciais sem previa autorização da SBG.

\section{Resumo}

Este texto apresenta os resultados de um levantamento geofísico realizado com o método do potencial espontâneo (SP) dentro do lixão de Cidade Nova, em Natal/RN. Os eletrodos não polarizáveis utilizados na aquisição de dados são de construção própria e os perfis obtidos sugerem que o chorume gerado no local apresenta um sentido de migração diferente do sentido de migração esperado para a água subterrânea.

\section{Introdução}

A disposição inadequada de resíduos sólidos urbanos gera diversos problemas ambientais. Dentre eles, a contaminação do solo por chorume caracterizase como um dos mais importantes, uma vez que pode comprometer a qualidade da água destinada ao abastecimento de áreas urbanas. Em Natal, capital do estado do Rio Grande do Norte, todos os resíduos produzidos desde o ano de 1972 eram destinados ao lixão de Cidade Nova (Figura 01). Como não havia meios adequados para recobrir todo o material depositado neste local, na maioria das vezes, ele era espalhado e compactado, prevalecendo o conceito de lixão a céu aberto (SILVA et al., 2005). Mesmo com a desativação do lixão, o volume de lixo depositado durante os 31 anos em que esteve em funcionamento ainda gera chorume e poucas pesquisas têm sido realizadas sobre os impactos ambientais causados ao lençol freático (VASCONCELOS et al., 2013; DA SILVA et al., 2005; FIGUEIREDO FF. 2006). Uma vez em subsuperfície, o chorume tende a migrar por caminhos preferenciais, tomando o mesmo sentido do fluxo subterrâneo (Figura 02).

A geofísica pode contribuir no monitoramento de áreas contaminadas por meio da aplicação de diversos métodos. Particularmente, quando se tem interesse em identificar fluxos subterrâneos, o método do espontâneo (SP) é largamente utilizado (SANTOS et al. 2014) por se tratar de um método de campo natural e que se baseia no fato de que, na ausência de um campo elétrico criado artificialmente, é possível medir uma diferença de potencial entre dois pontos na superfície do terreno que pode estar associada a concentrações de cargas elétricas em subsuperfície. Sua principal vantagem é simplicidade e os baixos custos operacionais (BORTOLIN et al., 2010). Em aplicações ambientais, o mecanismo que melhor explica a geração desses campos naturais é denominado potencial de fluxo. Segundo (GALLAS (2005): "O potencial de fluxo mais importante é o per descensum: trata-se da infiltração d'água da chuva em terrenos permeáveis ou ao longo de falhas/fraturas. Os cátions são removidos pela água e, nos locais topograficamente mais elevados, surgem núcleos eletricamente negativos". Deste modo, é possível determinar o sentido do fluxo subterrâneo: de áreas com potenciais elétricos mais baixos para áreas com potenciais elétricos mais elevados.

No entanto, é importante considerar que as amplitudes dos potenciais elétricos associados a campos naturais são, em geral, muito baixas. Por essa razão, torna-se necessário o uso de eletrodos não polarizáveis e de um voltímetro com alta impedância de entrada para medi-los. Esses cuidados são importantes, pois evitam que os potenciais elétricos associados à polarização de eletrodos metálicos possam sobrepor os potenciais naturais, de magnitude muito menor.

Neste contexto, os objetivos deste trabalho são: realizar um levantamento de SP dentro do lixão de Cidade Nova e confrontar os resultados obtidos com a hidrogeológia do local (Melo, 1995).

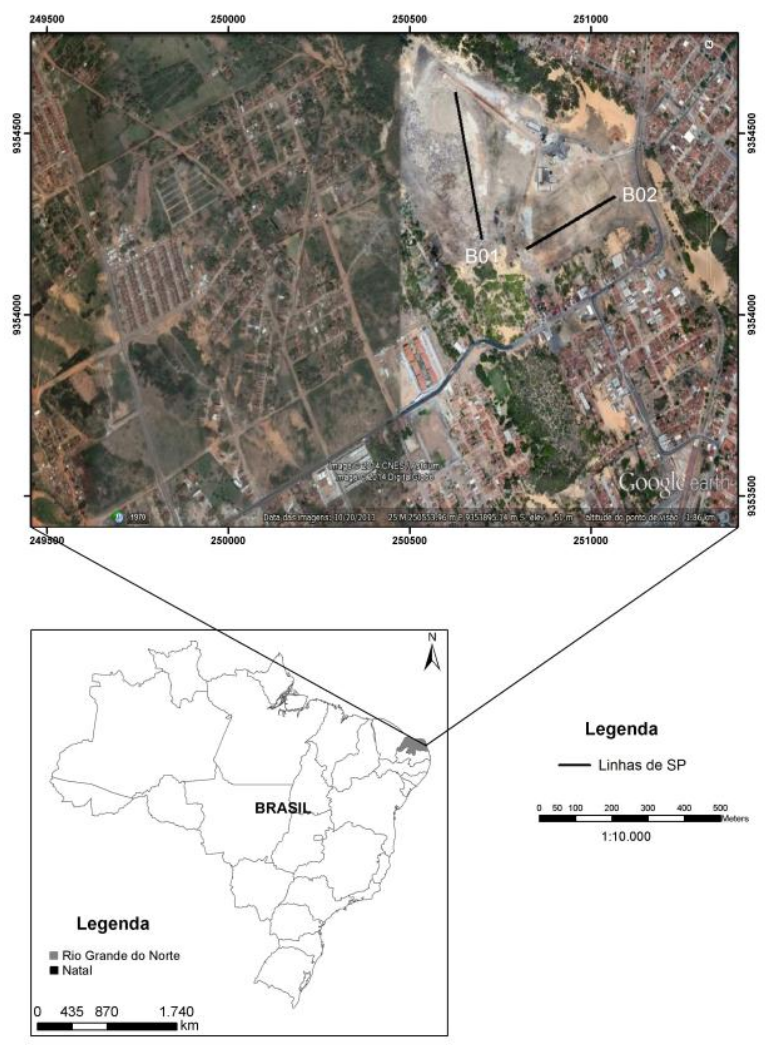

Figura 01 - Foto aérea do lixão de Cidade Nova em Natal/RN e localização das linhas de potencial espontâneo adquiridos (B01 e B02). 


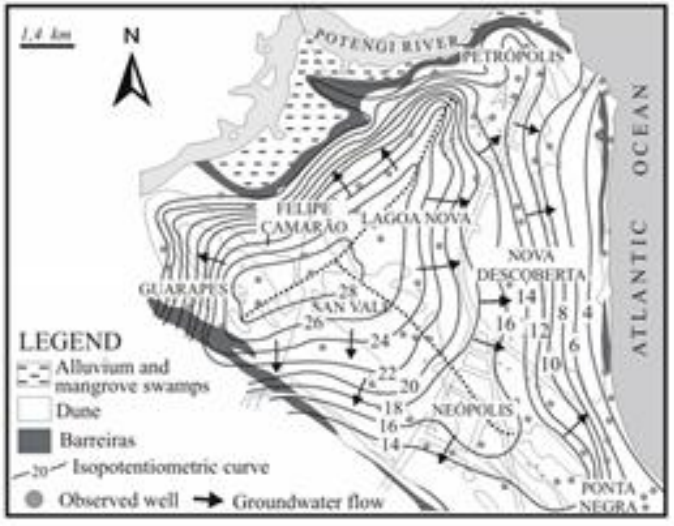

Figura 02 - Potenciometria do Sistema Aqüífero Dunas/Barreira Melo (1995).

\section{Metodologia}

A confecção dos eletrodos não polarizáveis baseouse no trabalho de OLIVEIRA E SOUSA et al., 2013. Foram utilizados tubos de PVC, um eletrodo de cobre em espiral e uma base porosa, responsável pela passagem do sulfato de cobre para o solo de modo lento e gradual. Para a base porosa adotou-se uma peça cerâmica comumente empregada em antigos filtros de água. Após a montagem, parte do conjunto foi envolvida em um tubo termo retrátil, deixando livre apenas a parte inferior da base porosa (Figuras 03 e 04).

$\mathrm{Na}$ aquisição dos dados utilizou-se a técnica da base fixa. Nesta técnica, um dos eletrodos é mantido fixo enquanto o outro é deslocado em intervalos regulares. $O$ espaçamento e o equipamento utilizados no levantamento foram, respectivamente, $30 \mathrm{~m}$ e um resistívimetro ABEM SAS 400, pertencente ao Departamento de Geofísica da Universidade Federal do Rio Grande do Norte (UFRN).

O acoplamento entre os eletrodos e o solo foi composto por uma pequena cava, preenchida com água e recoberta por areia (BUTLER, 2005). Antes de cada medida, esperamos alguns minutos até estabilizar a leitura de potencial. Foram adquiridos dois perfis de SP (B01 e B02), um na parte central e mais elevada do lixão (B01, Figura 01) e outro na parte mais baixa (B02, Figura 01). Na seção seguinte, apresentaremos os resultados associados a este levantamento.

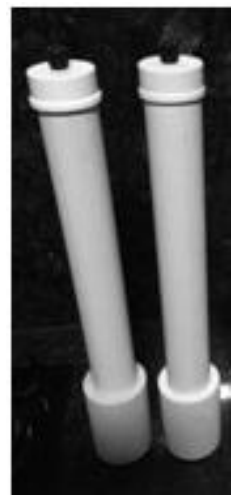

Figura 03 - Eletrodos não polarizáveis construídos com tubos de PVC, fios de cobre e bases cerâmicas.

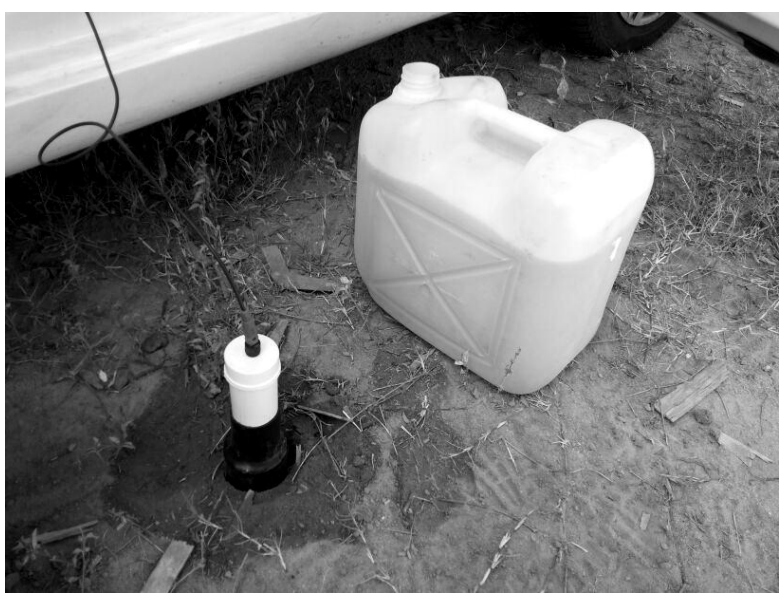

Figura 04 - Eletrodo base, utilizado na aquisição de SP.

\section{Resultados}

As Figuras 05 e 06 ilustram os perfis de SP B01 e B02. O perfil B01 (Figura 05) está localizado no coração do lixão de Cidade Nova, em sua parte mais elevada, e possui uma extensão de $360 \mathrm{~m}$. Apresenta potenciais elétricos variando de $-30.83 \mathrm{mV}$ a $8.77 \mathrm{mV}$. Já o perfil B02 (Figura 06) possui $270 \mathrm{~m}$, orientação nordeste e está inserido dentro de uma antiga área de deposição de resíduos (Hoje, aparentemente, em processo de reativação). Os potenciais elétricos medidos situam-se entre $12.94 \mathrm{mV}$ e $79.83 \mathrm{mV}$.

Ao comparar os dois perfis (B01 e B02), percebe-se que em B01 os potenciais elétricos são sistematicamente menores que no perfil B02. Admitindo que o mecanismo gerador de campos elétricos naturais no interior do lixão de Cidade Nova é - per descensum, pode-se definir o sentido de migração do chorume, aproximadamente, para sudeste. Este resultado se torna particularmente interessante quando confrontado com a potenciometria da área, que indica fluxo de água subterrânea, nas vizinhanças do lixão, para noroeste (Figura 02). Para entender como o contaminante interage com o Sistema Aqüífero Dunas/Barreira, tornam-se necessários estudos adicionais, integrando diversas metodologias.

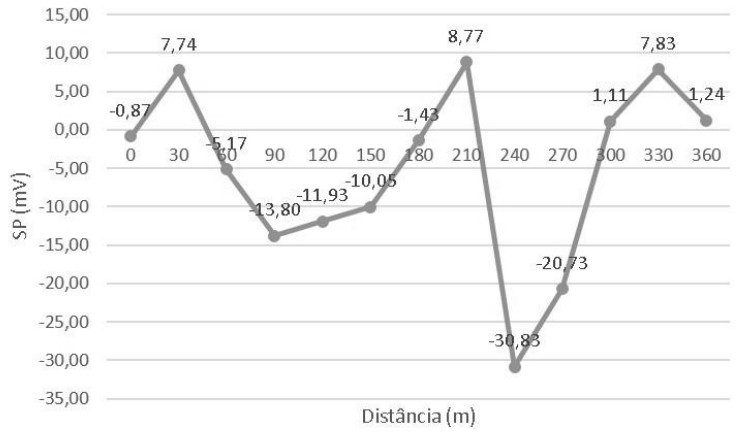

Figura 05 - Perfil de potencial espontâneo B01. 




Figura 06 - Perfil de potencial espontâneo B02.

\section{Conclusões}

Neste trabalho foram apresentados os resultados de um levantamento geofísico utilizando o método do potencial espontâneo com o objetivo de testar os eletrodos não polarizáveis e determinar o fluxo subterrâneo do contaminante gerado pela atividade do antigo lixão de cidade nova.

Foram realizados dois perfis de SP dentro do lixão, um na parte mais central e outro na parte mais baixa.

Os resultados mostram que os eletrodos construídos obtiveram uma resposta satisfatória e que o fluxo do contaminante não esta de acordo com o sentido do fluxo potenciometrico da região: o fluxo local é para noroeste e o fluxo do contaminante, definido a partir dos dados de SP, é para o sudeste.

\section{Agradecimentos}

Os autores agradecem ao $\mathrm{CNPq}$ pelo apoio financeiro (processo n478582/2011-0). A Companhia de Serviços Urbanos de Natal (URBANA) pela autorização de acesso a área de trabalho e pelo fornecimento de informações sobre o lixão de Cidade Nova. Ao Departamento de Geofísica da Universidade Federal do Rio Grande do Norte pelos equipamentos de campo, a Sociedade Brasileira de Geofísica pela bolsa de iniciação científica do primeiro autor deste trabalho e a Polícia Militar do Rio Grande do Norte, por promover a segurança da equipe durante os trabalhos de campo.

\section{Referências}

BORTOLIN, José Ricardo Melges. MALAGUTTI, Walter Filho. Método da eletrorresistividade aplicado no monitoramento temporal da pluma de contaminação em áreas de disposição de resíduos sólidos urbanos. In: Eng Sanit Ambient, v. 15 n. 4, out/dez 2010, p 367 - 374.

BUTLER, K. D. Near-surface geophysics. Ulsa, Oklahoma. Ed. SEG. 723p. 2005;

DA SILVA IR. GUIMARAES JRL. MORENO J C. 2005. Avaliação da quantidade de resíduos depositados no aterro sanitário metropolitano em relação ao antigo lixão de Cidade Nova. Anais do 23ํㅡㄹ Congresso Brasileiro de Engenharia Sanitária e Ambiental.
FIGUEIREDO FF. 2006. Esboço histórico da destinação dos resíduos do lixo em Natal, Brasil,período 1920 a 2003. Revista eletrônica de geografia y ciências sociales.

GALLAS, José Domingos Faraco. 2005. O método do potencial espontâneo (SP) - uma revisão sobre suas causas, seu uso histórico e suas aplicações atuais. In: Rev. Bras. Geof. vol.23 nํ 2. São Paulo: Apr./June 2005.

Melo, J. G., 1995. Impactos do Desenvolvimento urbano nas águas subterrâneas de Natal, RN. Instituto de Geociências da Universidade de São Paulo (USP). Tese de Doutorado. Oklahoma. Ed. SEG. 723p. 2005;

OLIVEIRA E SOUSA, Frederico Ricardo Ferreira Rodrigues de; BORGES, Welitom Rodrigues; CAVALCANTI, Márcio Maciel; GAUDÊNCIO, Guilherme Meirelles da Motta de Figueiredo; MENDES, Paulo Kleber Machado Filho; PINHEIRO, Arthur Nogales Domenici Vasconcellos. The Self-Potential (SP) method applied for investigating the contamination in the vicinity of the Estrutural city landfill, in Brasilia-DF. In: 13th International Congress of the Brasilian Geophysical, 2007, Rio de Janeiro. Brazil.

SANTOS, Ana Carolina Oliveria dos; MELLO, Fernanda Vargas de; KAMPHORST, Juliana de Souza Corrêa; MOREIRA, César Augusto. Estudos geoelétricos em aterro controlado no município de Caçapava do Sul - RS. In: Revista Eletronica em Gestão, Educação e Tecnologia Ambiental - REGET. V. 18 n. 1 Abr 2014, p. 99-112.

SILVA, Emília Margareth de Melo; MENESES, Carla Gracy Ribeiro; MORENO, Josivan Cardoso. Degradação ambiental da área do lixão de cidade nova devido ao acúmulo de resíduos sólidos. In: $23^{\circ}$ Congresso Brasileiro de Engenharia Sanitária e Ambiental, 2005, Campo Grande/MS.

VASCONCELOS, Bruno Raphael Morais de; OLIVEIRA, Josibel Gomes de Oliveira Júnior; MEDEIROS, Walter Eugênio de. Aplicação do método da eletrorresistividade em uma área contaminada por chorume na região metropolitana de Natal/RN. In: 13th International Congress of the Brazilian Geophysical Society. 2013, Rio de Janeiro, Brazil. 